\title{
KEMAMPUAN ADSORBEN LIMBAH LATEKS KARET ALAM TERHADAP MINYAK PELUMAS DALAM AIR
}

\author{
Edward Tandy, Ismail Fahmi Hasibuan, Hamidah Harahap \\ Departemen Teknik Kimia, Fakultas Teknik, Universitas Sumatera Utara, \\ Jalan Almamater Kampus USU Medan 20155, Indonesia \\ e-mail: edward.tandy.ce@gmail.com
}

\begin{abstract}
Abstrak
Limbah lateks karet alam yang seyogyanya dibuang menjadi bahan tidak berguna dan menyebabkan masalah lingkungan. Salah satu cara mengurangi masalah lingkungan ini dengan memanfaatkan limbah lateks karet alam sebagai adsorben minyak. Limbah lateks karet alam memiliki sifat oleofilik dan hidrofobik yang cocok untuk dijadikan adsorben minyak. Pada penelitian ini, peneliti mencari kemampuan adsorpsi limbah lateks karet alam terhadap minyak dan minyak dalam air serta karakteristik adsorpsinya dengan persamaan isoterm adsorpsi Langmuir dan isoterm adsorpsi Freundlich. Karakteristik adsorpsi minyak pelumas dari air dengan limbah lateks karet alam lebih cocok dengan persamaan isoterm Langmuir dan kemampuan adsorpsi maksimum minyak pelumas dalam air dengan limbah lateks karet alam juga meningkat dengan bertambahnya waktu kontak hingga mencapai kesetimbangan. Hasil penelitian ini menyimpulkan limbah lateks karet alam ini mempunyai daya adsorpsi minyak yang cukup besar dan cocok dijadikan sebagai adsorben minyak.
\end{abstract}

Kata Kunci : limbah lateks karet alam, minyak dalam air, adsorpsi, kesetimbangan adsorpsi, adsorben minyak

\begin{abstract}
Natural rubber latex waste usually throw away to be unused materials and caused environment issue. One of the ways to handle this environment issue by using natural rubber latex waste as oil adsorbent. Natural rubber latex waste also had oleophilic and hydrophobic properties that are suitable to being used as oil adsorbent. In this research, researchers found out adsorption capacity of natural rubber latex waste to oil and oil from water, also the characteristics of it's adsorption with Langmuir and Freundlich isoterm adsorption model. The adsorption characteristics of lubricant oil from water with natural rubber latex waste more fitted well with Langmuir isotherm equation model and the maximum adsorption ability of lubricant oil from water with natural rubber latex waste also significantly increased with the contact time till reached the equilibrium. The results of this study concluded that natural rubber latex waste had a great adsorption capacity and suitabled for being used as oil adsorbent.
\end{abstract}

Keywords : natural rubber latex waste, oil in water, adsorption, adsorption equilibrium, oil adsorbent

\section{Pendahuluan}

Kebanyakan produk lateks karet alam diproduksi menggunakan pra-vulkanisasi lateks. Metode konvensional ini melibatkan pencampuran langsung lateks karet alam dengan bahan aditif seperti sulfur, akselerator, aktivator, stabilizer dan antioksidan, dan kemudian campuran dipanaskan dengan temperatur dan waktu tertentu. Bahan yang dihasilkan ini dinamakan pra-vulkanisasi lateks karet alam yang akan digunakan untuk membuat produk lateks karet alam. Metode ini menghasilkan limbah lateks yang cukup banyak. Limbah lateks karet alam ini terbentuk ketika lateks pra-vulkanisasi mengalami overcured sewaktu penyimpanan ataupun pemrosesan. Lateks karet alam overcured ini biasanya dibuang dan menjadi limbah karena produk yang dibentuk dengan lateks karet alam ini biasanya mempunyai sifat-sifat yang buruk [3].

Salah satu cara menanggulangi limbah lateks karet alam ini adalah memanfaatkannya sebagai adsorben minyak. Berbagai limbah karet dapat dijadikan adsorben minyak yang mampu membersihkan tumpahan minyak di tanah dan dapat menjerap 5 kali beratnya di air [5]. Kemudian partikel karet ban bekas memiliki kemampuan adsorpsi sebesar 0,84 g.g ${ }^{-1}$ untuk minyak pelumas dan $0,87 \mathrm{~g} \cdot \mathrm{g}^{-1}$ untuk minyak jelantah [6]. Atas dasar inilah, peneliti ingin memanfaatkan limbah lateks yang overcured untuk dijadikan adsorben minyak.

Dalam penelitian ini, peneliti akan membuat adsorben dari limbah lateks karet alam yang overcured, kemudian mencari kemampuan adsorpsi minyak dan minyak dari air serta karakteristik adsorpsinya dengan persamaan isoterm adsorpsi Langmuir dan isoterm adsorpsi Freundlich.

\section{Teori}

Adsorpsi

Adsorpsi merupakan suatu proses penyerapan oleh padatan tertentu terhadap zat tertentu yang terjadi pada permukaan zat padat karena adanya gaya tarik atom atau molekul pada permukaan zat padat tanpa meresap ke dalam. Proses adsorpsi dapat terjadi karena adanya gaya tarik atom atau molekul pada permukaan padatan yang tidak seimbang. Adanya gaya ini, padatan 
cenderung menarik molekul-molekul yang lain yang bersentuhan dengan permukaan padatan, baik fasa gas atau fasa larutan ke dalam permukaannya. Akibatnya, konsentrasi molekul pada permukaan menjadi lebih besar dari pada dalam fasa gas atau zat terlarut dalam larutan. Adsorpsi dapat terjadi pada antarfasa padatcair, padat-gas atau gas-cair. Molekul yang terikat pada bagian antarmuka disebut adsorbat, sedangkan permukaan yang menyerap molekul-molekul adsorbat disebut adsorben. Pada adsorpsi, interaksi antara adsorben dengan adsorbat hanya terjadi pada permukaan adsorben. Adapun faktor-faktor yang mempengaruhi proses adsorpsi adalah luas permukaan, jenis adsorbat, konsentrasi adsorbat, temperatur, $\mathrm{pH}$, kecepatan pengadukan dan waktu kontak adsorpsi [8]. Adsorben

Adsorben merupakan bahan yang sangat berpori, dan adsorpsi berlangsung terutama pada dindingdinding pori atau pada letak-letak tertentu di dalam partikel itu. Karena pori-pori itu biasanya sangat kecil, luas perrmukaan dalam menjadi beberapa orde besaran lebih besar dari permukaan luar, dan bisa sampai 2.000 $\mathrm{m}^{2} / \mathrm{gr}$. Pemisahan terjadi karena perbedaan bobot molekul atau karena perbedaaan polaritas menyebabkan sebagian besar molekul melekat pada permukaan itu lebih erat daripada molekul-molekul lainnya. Dalam kebanyakan hal, komponen yang diadsorpsi melekat sedemikian kuat sehingga memungkinkan pemisahan komponen itu secara menyeluruh dari fluida tanpa terlalu banyak adsorbsi terhadap komponen lain. Regenerasi adsorben dapat dilaksanakan kemudian mendapatkan adsorbat dalam bentuk terkonsentrasi atau hampir murni [7].

Isoterm Adsorpsi

Isoterm adsorpsi adalah hubungan kesetimbangan antara konsentrasi dalam fase fluida dan konsentrasi di dalam partikel adsorben pada suhu tertentu. Pada adsorpsi minyak dari air ini, digunakan persamaan isoterm Freundlich dan isoterm Langmuir. Adapun data kuantitatif yang didapat dari penelitan berupa daya jerap minyak per gram adsorben (q) dan konsentrasi minyak akhir pada air (c) selama waktu kontak maksimum ditentukan dengan persamaan isotherm adsorpsi Freundlich dan persamaan isotherm adsorpsi Langmuir untuk mengetahui karakteristik adsorpsi minyak oleh adsorben sedangkan daya adsorpsi maksimum dari adsorben dengan membuat kurva berdasarkan karakteristik yang diperoleh.

Persamaan isoterm Freundlich ini biasanya digunakan adsorpsi gas hidrokarbon dengan karbon aktif dan isoterm Langmuir sangat cocok untuk proses adsorpsi unimolekular dan adsorpsi reversible. Berikut adalah persamaan isoterm adsorpsi Freundlich dan Langmuir.

Persamaan Isotherm Freundlich:

$$
\mathrm{q}=\mathrm{K}_{\mathrm{f}} \cdot \mathrm{c}^{\mathrm{n}} \text { atau } \log \mathrm{q}=\log \mathrm{K}_{\mathrm{f}}+\mathrm{n} \cdot \log \mathrm{c}
$$

$\mathrm{c}=$ konsentrasi adsorbat dalam fluida (air) $(\mathrm{g}$ adsorbat/ $\mathrm{dm}^{3}$ fluida)

$\mathrm{n}$ dan $\mathrm{K}$ ( $\mathrm{dm}^{3}$ fluida/ $\mathrm{g}$ adsorben) adalah

konstanta dan didapat dari percobaan

Persamaan Isotherm Langmuir:

$\mathrm{q}=\frac{\mathrm{q}_{\mathrm{o}} \mathrm{c}}{\mathrm{K}+\mathrm{c}} \quad$ atau $\quad \frac{\mathrm{c}}{\mathrm{q}}=\frac{\mathrm{K}}{\mathrm{qo}}+\frac{1}{\mathrm{qo}} \cdot \mathrm{c}$

dimana: qo = daya jerap maksimum (g adsorbat $/ \mathrm{g}$ adsorben)

$\mathrm{q}$ = daya jerap ( $\mathrm{g}$ adsorbat/ $\mathrm{g}$ adsorben)

$\mathrm{c}=$ konsentrasi adsorbat dalam fluida (air) ( $\mathrm{g}$ adsorbat $/ \mathrm{dm}^{3}$ fluida)

$\mathrm{K}$ (g adsorbat/ $\mathrm{dm}^{3}$ fluida) adalah konstanta

dan didapat dari percobaan [4].

Limbah Lateks Karet Alam

Limbah lateks karet alam yang digunakan pada penelitian ini adalah lateks overcured yang terbentuk pada saat pra vulkanisasi lateks karet alam dengan metode konvensional. Metode konvensional ini melibatkan pencampuran langsung lateks karet alam dengan bahan aditif seperti sulfur, akselerator, aktivator, stabilizer dan anti oksidan, dan kemudian dimatangkan dengan cara memanaskan campuran dengan temperatur yang sesuai selama waktu tertentu. Limbah lateks karet alam ini terjadi ketika lateks mengalami overcured pada saat penyimpanan ataupun pemrosesan yaitu saat pra-vulkanisasi biasanya suhu vulkanisasi yang terlalu tinggi dan waktu curing yang lama. Lateks overcured ini biasanya dibuang dan menjadi limbah karena produk yang dibentuk dengan lateks ini biasanya mempunyai sifat-sifat yang buruk [3].

\section{Metodologi Penelitian}

Pembuatan Limbah Lateks Karet Alam Menjadi Adsorben Minyak

Limbah lateks karet alam yang digunakan adalah lateks yang overcured, kemudian dikeringkan dalam oven pada suhu $110^{\circ} \mathrm{C}$ selama 5 jam. Setelah itu ukuran limbah lateks diperkecil hingga diameter 1-3 mm. Adsorben disimpan dalam wadah tertutup.

\section{Daya Adsorpsi Minyak oleh Adsorben Minyak}

Adsorben sebanyak $2 \mathrm{~g}$ dimasukkkan ke dalam beaker glass yang berisi $100 \mathrm{ml}$ minyak pelumas. Adsorpsi dihentikan dengan variasi waktu 15, 30,45, 60,75, 90, 105 dan 120 menit. Adsorben disaring dan dicatat berat akhirnya, kemudian dicari daya adsorpsi tiap variasi waktu dengan persamaan (3).

Daya adsorpsi dapat dicari dengan rumus :

$$
q=\frac{W-W_{o}}{W_{o}}
$$

dimana: $\mathrm{q}$ = Daya adsorpsi ( $\mathrm{g}$ minyak/g adsorben)

$$
\begin{aligned}
& \mathrm{W}_{\mathrm{o}}=\text { Berat adsorben mula }- \text { mula }(\mathrm{g}) \\
& \mathrm{W}=\text { Berat adsorben akhir }(\mathrm{g})
\end{aligned}
$$

dimana: $\mathrm{q}=$ daya jerap ( $\mathrm{g}$ adsorbat/ $\mathrm{g}$ adsorben) 
Waktu Optimal Adsorpsi Minyak Pelumas dalam Air oleh Adsorben Minyak

Sebanyak $6 \mathrm{~g}$ minyak pelumas dimasukkan dalam beaker glass berisi $100 \mathrm{ml}$ air. Kemudian dimasukkan 4 $\mathrm{g}$ adsorben minyak dan diaduk dengan magnetic stirrer dengan kecepatan $170 \mathrm{rpm}$. Agitasi dihentikan pada waktu 2, 5, 15, 30 dan 60 menit. Adsorben disaring dan dicatat berat akhirnya. Filtrat minyak-air dianalisa kadar minyaknya dengan heksana (US EPA Method 10056). Kemudian dihitung daya adsorpsi adsorben dengan persamaan (4).

$$
q=\frac{\left(c_{o}-c\right) V}{W}
$$

dimana $: \mathrm{q}=$ Daya adsorpsi ( $\mathrm{g}$ minyak/ $\mathrm{g}$ adsorben $)$

$\mathrm{W}=$ Berat adsorben $(\mathrm{g})$

$\mathrm{c}_{\mathrm{o}}=$ Konsentrasi awal minyak pelumas dalam air (g minyak/ L larutan)

c $=$ Konsentrasi akhir minyak pelumas dalam air (g minyak/ L larutan)

$\mathrm{V}=$ Volume Larutan $(\mathrm{ml})$

Karakteristik Adsorpsi Minyak Pelumas dalam Air dengan Adsorben Minyak

Sebanyak $4 \mathrm{~g}$ adsorben dimasukkan ke dalam beaker glass yang berisi $100 \mathrm{ml}$ air dengan variasi berat minyak 2, 4, 6, 8 dan $10 \mathrm{~g}$. Diaduk dengan magnetic stirrer dengan kecepatan $170 \mathrm{rpm}$. Agitasi dihentikan pada waktu kontak optimal. Adsorben disaring dan dicatat berat akhirnya. Filtrat minyak-air dianalisa kadar minyaknya dengan heksana (US EPA Method 10056). Kemudian dihitung daya adsorpsi adsorben dengan persamaan (4).

\section{Hasil}

Daya Adsorpsi Minyak oleh Adsorben Minyak

Kurva hubungan daya adsorpsi minyak terhadap waktu kontak disajikan pada Gambar 1.

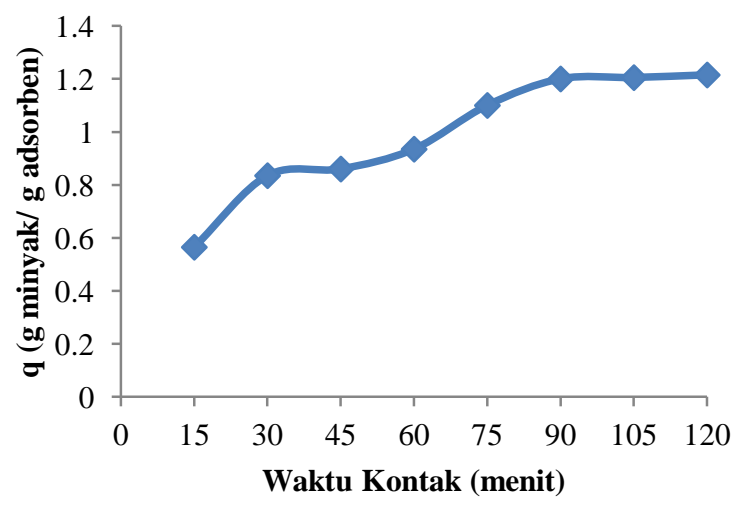

Gambar 1. Kurva Hubungan Daya Adsorpsi Minyak Pelumas oleh Adsorben Minyak terhadap Waktu Kontak ( $\mathrm{T}=30^{\circ} \mathrm{C} ; 2$ gram adsorben; tanpa pengadukan)

Pada Gambar 1 dapat dilihat daya adsorpsi minyak oleh adsorben minyak terus meningkat seirama dengan bertambahnya waktu kontak. Semakin lama waktu kontak, semakin besar daya adsorpsi yang dicapai hingga tercapai kesetimbangan [9].

Adapun $2 \mathrm{~g}$ adsorben minyak digunakan untuk mengadsorpsi minyak dalam waktu 15 - 120 menit dan dihitung daya adsorpsi minyak pelumas dengan selang waktu 15 menit. Daya adsorpsi minyak oleh adsorben minyak mulai konstan pada menit ke-90. Hal ini terjadi karena adsorpsi minyak pelumas oleh adsorben minyak dari limbah lateks merupakan peristiwa kesetimbangan [2]. Dan didapat daya adsorpsi minyak maksimum pada menit ke-105 sebesar 1,205 g minyak/g adsorben .

Waktu Optimal Adsorpsi Minyak Pelumas dalam Air oleh Adsorben Minyak

Kurva hubungan daya adsorpsi minyak dalam air oleh adsorben minyak terhadap waktu kontak disajikan pada Gambar 2.

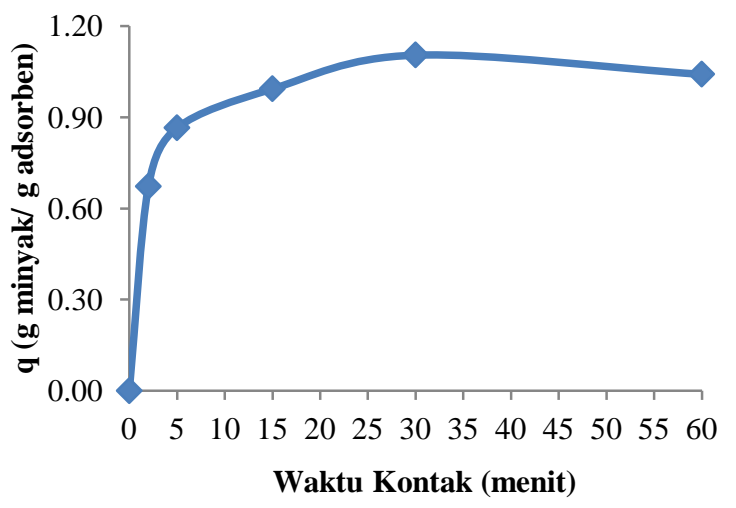

Gambar 2. Kurva Hubungan Daya Adsorpsi Minyak Pelumas dalam Air oleh Adsorben Minyak terhadap Waktu

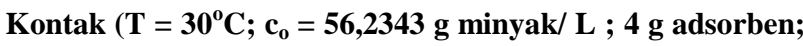
170 rpm)

Dalam hal adsorpsi minyak pelumas dari air ini, diharapkan adsorben minyak harus memiliki sifat oleofilik dan hidrofobik sehingga bisa menjerap minyak dari air [1]. Dan limbah lateks ini memiliki sifat oleofilik dan hidrofobik, sehingga cocok dijadikan adsorben minyak.

Dari gambar 2 dapat dilihat daya adsorpsi minyak pelumas dalam air oleh adsorben berlangsung cepat pada awal adsorpsi, kemudian mulai konstan pada menit ke-15 dan daya adsorpsi maksimum minyak pelumas dari air oleh adsorben minyak terjadi pada menit ke-30. Hal ini terjadi karena adsorpsi minyak pelumas dalam air oleh adsorben minyak dari limbah lateks merupakan peristiwa kesetimbangan [2]. Waktu optimal adsorpsi minyak pelumas dalam air oleh adsorben minyak dari limbah lateks adalah 30 menit.

Karakteristik Adsorpsi Minyak Pelumas dalam Air dengan Adsorben Minyak

Untuk mengetahui karakteristik adsorpsi minyak oleh adsorben dilakukan dengan mengamati jerapannya terhadap minyak dalam air pada konsentrasi yang 
bervariasi dari 19,5633 g/L sampai 89,9598 g/L dan pada suhu isoterm sekitar $30^{\circ} \mathrm{C}$. Dari hasil penjerapan tersebut selanjutnya dianalisis menggunakan persamaan isoterm adsorpsi Freundlich dan isoterm adsorpsi Langmuir untuk mengetahui karakteristik adsorpsi dan juga daya adsorpsi maksimumnya. Berikut adalah kurva linearitas Freundlich dan Langmuir pada Gambar 3 dan 4.

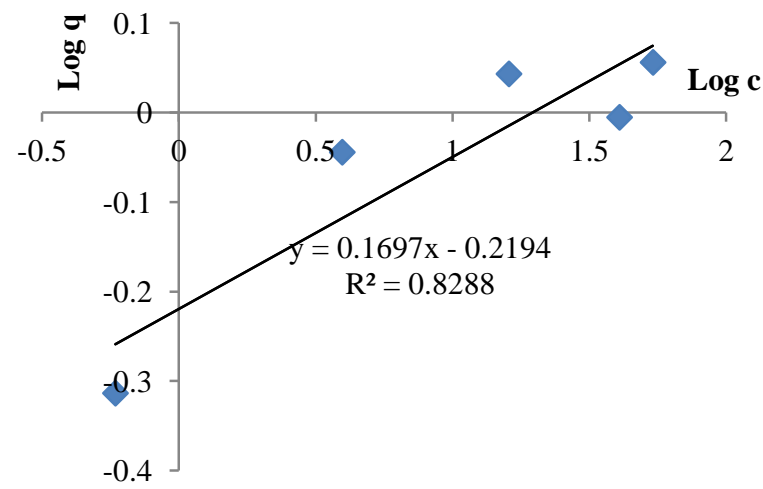

Gambar 3. Kurva Linearitas Freundlich: Hubungan antara $\log c$ terhadap $\log q$ pada Adsorpsi Minyak Pelumas dalam Air oleh Adsorben Minyak $\left(\mathrm{T}=30^{\circ} \mathrm{C} ; 4 \mathrm{~g}\right.$ adsorben; 170 rpm)

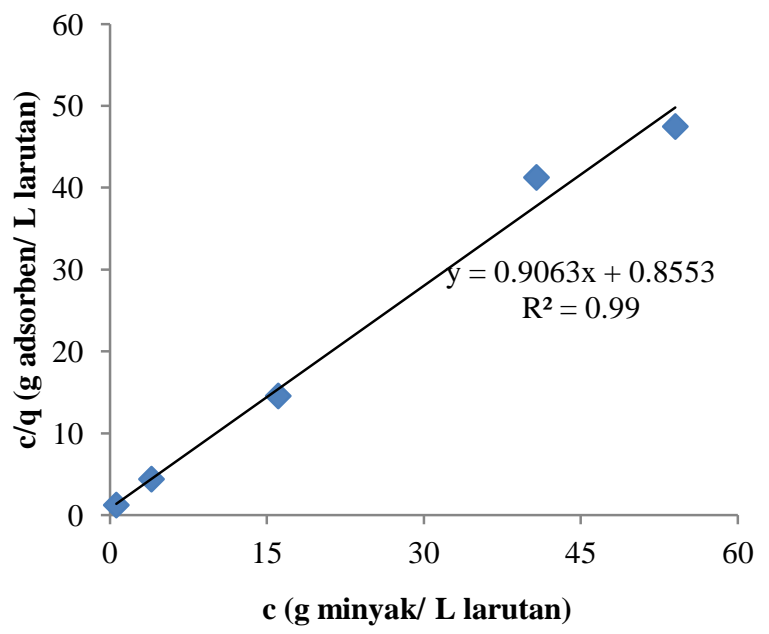

Gambar 4. Kurva Linearitas Langmuir: Hubungan Antara c terhadap c/q pada Adsorpsi Minyak Pelumas dalam Air oleh Adsorben Minyak $\left(\mathrm{T}=30^{\circ} \mathrm{C} ; 4 \mathrm{~g}\right.$ adsorben; 170 rpm)

Berdasarkan nilai $\mathrm{R}^{2}$, persamaan isoterm Langmuir lebih cocok untuk adsorpsi minyak pelumas dari air oleh adsorben minyak. Nilai $\mathrm{R}^{2}$ untuk isoterm Langmuir sebesar 0,99 sedangkan untuk isoterm Freundlich adalah 0,828 . Ini disebabkan minyak yang digunakan adalah minyak pelumas yang terdiri dari senyawa-senyawa yang berantai panjang dan mempunyai berat molekul yang besar. Sehingga adsorpsi minyak dari air oleh adsorben yang mengikuti persamaan isoterm Langmuir yang mana adsorbat hanya teradsorpsi secara unimolekular ke permukaan adsorben [11].

Kurva isoterm adsorpsi Langmuir, selanjutnya dapat dipakai untuk menentukan daya adsorpsi maksimum $\left(\mathrm{q}_{\mathrm{o}}\right)$ yaitu berdasarkan nilai dari slope (kemiringan garis) pada persamaan $\mathrm{Y}=0,906 \mathrm{X}+$ 0,855 , yaitu $1 / \mathrm{q}_{\mathrm{o}}$. Dengan mensubstitusi $1 / \mathrm{q}_{\mathrm{o}}=0,906$ maka diperoleh nilai $\mathrm{q}_{\mathrm{o}}=1,1038 \mathrm{~g}$ minyak/ $\mathrm{g}$ adsorben. Kemampuan adsorpsi maksimum minyak dalam air oleh adsorben minyak diperoleh sebesar 1,1038 $\mathrm{g}$ minyak/g adsorben.

\section{Kesimpulan}

Adsorben minyak dari limbah lateks ini mempunyai daya adsorpsi minyak sebesar $1,205 \mathrm{~g} . \mathrm{g}^{-1}$ pada minyak pelumas dan sebesar $1,1038 \mathrm{~g} . \mathrm{g}^{-1}$ pada minyak pelumas dalam air. Karakteristik adsorpsi minyak pelumas oleh adsorben ini lebih menyerupai persamaan isoterm adsorpsi Langmuir karena adsorpsi bersifat unimolekular. Sehingga limbah lateks dapat dimanfaatkan menjadi adsorben minyak dengan kemampuan adsorpsi minyak yang cukup besar.

\section{Daftar Pustaka}

[1] Aronu, U. E, Absorption Mats for Oil Decontamination. Master of Science Thesis, Univ. College of Borås, Sweden, 2007.

[2] Atkins, P.W, Kimia Fisika. Jilid 2, Edisi Keempat. Erlangga, Jakarta, 1990.

[3] Azahari, Baharin., Yan P. Meng., Marzio Ahmad., Yusof Mohd. dan Arif, N. Zainal, Addition of over cured latex to compounded uncompounded and prevulcanised HA latex. Natural Rubber Curing Development In Product Manufacture and Applications : A report of proceeding of the International Rubber Technology Conference, RRIM, 1993.

[4] Geankoplis, Christie J, Transport Processes and Separation Process Principles. Fourth Edition, Prentice Hall, 2003.

[5] Ismail, Hanafi, OilZob: A Novel and Reactive Oil Adsorbent from Various Rubber Wastes, Universitas Sains Malaysia, 2005.

[6] Kania, Dina., Soewondo, Prayatni., dan Valdes, Julio R, Pemisahan Minyak Pelumas Dan Minyak Jelantah Dari Air Melalui Absorpsi Pada Partikel Karet Ban, ITB, 2010.

[7] Mc Cabe, Warren L, Unit Operation of Chemical Engineering. McGraw-Hill Book Inc, 1999.

[8] Noviati, Rizka, Perbandingan Daya Absorbsi Ion $\mathrm{Cr}^{3+}$ Pada Serbuk Gergaji Kayu Albizia Dengan Zeolit Ditinjau Dari Teori HSAB. FMIPA. Universitas Brawijaya Malang, 2011. 
[9] Perdana, Wahyu N. Reka, Adsorpsi Cr(VI) dengan Menggunakan Abu Sekam Padi Sebagai Adsorben, Tesis, ITS, 2008.

[10] Tri, Phan Thanh, Oily Wastewater Treatment By

Membrane Bioreactor Process Coupled with Biological Activated Carbon Process. Thesis. Asian Institue of Technology, Thailand, 2002. 